\title{
Javanese Muslim with Diabetes in Yogyakarta Managing The Daily Self-Care Activity
}

\author{
Iman Permana ${ }^{1}$, Muflikh Try Harbiyan ${ }^{2}$ \\ ${ }^{1}$ Centre of Islamic Medicine Studies; Department of Community Health and Family Medicine, \\ Universitas Muhammadiyah Yogyakarta, Indonesia \\ ${ }^{2}$ Faculty of Medicine and Health Sciences, Universitas Muhammadiyah Yogyakarta, Indonesia
}

\begin{abstract}
Article Info
Article history:

Received Aug 3, 2015

Revised Sep 20, 2015

Accepted Oct 26, 2015

\section{Keyword:}

Diabetes management

Javanese way

Religion

SDSCA

Self-care

ABSTRACT

Self-care, capability in performing certain activity in maintaining well-being in daily life, was regarded important especially among people with long-term condition such as diabetes. Locus of control and self-efficacy are among the self-agency factors that might influence how people engage with daily selfcare activity in diabetes management. While, Javanese and Islamic values and norms are other parts of structure that support the effort. This study aimed to seek further into the experiences and perceptions among the Javanese Muslim on how they managed to do self-care in diabetes management. The study was done utilizing a mixed method approach with the usage of the Summary of Diabetes Self-care Activity (SDSCA) questionnaire to measure the level of self-care and followed by further interview to dig deeper into the perception and experiences and what are the opportunity or obstacle in performing daily self-care. A convenient sample of 100 participants has filled the questionnaires, with further 24 interviews. The study identified the moderate self-care practices as a separate notion, instead of an integrated and comprehensive concept amid the unavailability of a structured education program. Five themes were generated from the interviews, those are: education and knowledge, being in or out of control, Javanese way - sensitivity and surrender, peace of mind and role of Allah or God, and poor access to health care.
\end{abstract}

Copyright (C) 2015 Institute of Advanced Engineering and Science. All rights reserved.

\section{Corresponding Author:}

Iman Permana,

Centre of Islamic Medicine Studies,

Department of Community Health and Family Medicine,

Universitas Muhammadiyah Yogyakarta,

Kampus Terpadu, Jl Lingkar Selatan, Kasihan, Bantul, Yogyakarta, Indonesia.

Email: imanpermana@umy.ac.id

\section{INTRODUCTION}

\subsection{Diabetes}

Diabetes is a chronic metabolic disease that can be developed when the body is not sufficiently producing insulin or can not use insulin efficiently [1]. The prevalence of diabetes has been increasing for the last several decades. According to the International Diabetes Federation's report (2013), more than a third of a billion people (381 million) across the globe suffer from this illness, and this represents an increase of more than 50\% from 246 million in 2007 [2]. Thus, it is predicted to reach more than half a billion (591 million) in 2035 . The majority of cases $(80 \%)$ come from low and middle income countries, which shows a misconception that diabetes is an illness of the wealthy. Indonesia has the fourth largest population in the world after the United States, India and China [3]. With around 239 million people, diabetes prevalence accounts for $4.8 \%$ in 2010 [4], with the trend of the prevalence is significantly increasing and estimated to increase further to $5.9 \%$ in 2030 . Indeed this prediction will place Indonesia in the ninth position of the ten 
countries with the most prevalent diabetes in the world in 2030 [5]. While according to the update data from the International Diabetes Federation (2012b), Indonesia has moved to the seventh position.

Furthermore, this illness and its particular complications, such as kidney failure, heart diseases, limb amputations and blindness, have been responsible for high mortality rates across the globe. The World Health Organization reported in 2004 that 3.4 million deaths have occurred due to the consequences of high blood sugar [6]. Moreover, the burdens are also affecting not only physically, but also psychologically. Therefore, a more comprehensive treatment is considered to be crucial in managing this condition. Indeed, it is believed that preventive measures such as modyfing lifestyle, lowering body weight, keeping physically active, are beneficial in decreasing the incidence of diabetes, as well as preventing the complications from occurred.

According to Riskesdas 2010 or the Basic Health Research 2010 reports in Indonesia (Commision on Health Development and Research, 2010), the obesity rate for children between 6 to 12 years old was $9.2 \%$, while for people older than 18 years old it was 11.7\% [7]. Moreover, the Country Health Report from WHO (2006) shows that the main health problems in Indonesia were associated with changes in food habit [8]. For example, the popularity of fast food among adults and children is associated with the higher incidence of obesity. In addition, there is an increasing trend of smoking among young people, which will cause lifestyle related health problems. Other problems that also account for health problems are substances abuse, lack of exercise, sedentary lifestyle and violence. Lack of social support and national commitment, despite several public health initiatives have been implemented, is identified as main obstacles in managing these problems, especially smoking [8].

\subsection{Self-Care}

Self-care refers to the actions that people take in promoting health, preventing and detecting any illnesses, also in self-treatment [9]. Similar definitions exist, demonstrating worldwide consensus of understanding 'self-care is the ability of individuals, families and communities to promote health, prevent disease and maintain health and to cope with illness and disability with or without the support of a healthcare provider' [10].

Several studies identify the series of self-care activities in diabetes management consisting of conducting dietary regulation, keeping physically active, adhere to the medication, performing foot care, and self-monitoring blood glucose [11],[12]. Furthermore, guidelines from both the International Diabetes Federation (IDF, 2012), and the Indonesian Endocrinologist Association (Perkeni, 2011) emphasize the importance of self-care activities to prevent the risk of complications for people with diabetes, as well as enhance quality of life [5],[13]. Indeed, maintaining a healthy lifestyle and establishing a normal body weight may prevent the development of diabetes as well as potential complications [6],[9]. Unlike established international diabetes management programs (UK or US), within Indonesia the management of diabetes is not considered a comprehensive and integrated program, with only partial recommendations into separate self-care activity for optimum diabetes care being introduced due to cost and health care structure [14]-[16].

\subsection{Determinant factors in diabetes management}

Self-care is a concept that entails multi aspects of human behavior. However, there are several factors that can potentially influence an individual and enhance or reduce self-care activities and behaviour. Recently, new health agendas identify that health experiences are influenced not only by genetics, or lifestyle but also by a wide range of social, economic, political and environmental factors [17]. The concept of agency and structure are important underlying factors that might influence self-care behavior [18]. Agency refers to the capacity of individuals to make decision toward a course of action based on their past experiences, future and present conditions [19], whereas, structure refers to any social norms, regulations, rules and resources available, either human or non-human [18]. Thus, education has served as a critical point in self-agency [18].

Evidences reveal the determining factor of self-efficacy [20] and locus of control [21] as underlying factors that might effect someone in maintaining their daily activity; supporting the decision making and how they behave to particular events in their lives. Furthermore, religion/spirituality [22]-[24] as well as healthcare access, and social support [25]-[27] have served as external resources for the people in maintaining their long term condition.

\section{RESEARCH METHOD}

This study was conducted utilizing a mixed method approach. The deployment of SDSCA was intended as a screening tool to gain particular participants for interview. Creswell (2014) regards this approach as a sequential explanatory approach [28]. The population of the study was type 2 diabetic patients from the out-patients of the Internal Medicine clinic from a private hospital in Yogyakarta, Indonesia. According to the 2010 database there were 610 cases of diabetes, which were not classified into types. 
Purposive sampling method was utilized and the sample was selected using the following inclusion criteria: over 18 years old, male and female, diagnosed with type 2 diabetes for over 12 months, under the care of a consultant and being treated according to the Indonesian Endocrinologist guideline or Perkeni (2011) [13]. Patients would be excluded if they were diagnosed and were being treated for a mental health problem, this was to ensure that they were competent to provide consent to be involved in the study.

The sample for the questionnaire was gained through direct approaches in the waiting room's clinic. During a three month data collection period 100 respondents were recruited out of 201 approach to gain a wider perspective of the self-care activity of the people accessing the clinic.

The SDSCA questionnaires results were used to inform the classification of participants into three levels of high, moderate and low and sought further into various dimension of self-care activities. Semistructured interview was conducted following the result of the questionnaires to dig deeper into the perceptions and experiences of the participants. Purposive sampling technique was also performed in collecting the sample for the interviews, to gain a richer and wider perspective of the sample. The interviews were transcribed verbatim and thematic content analysis was performed to generate themes. All names were pseudonyms to maintain confidentiality of the study.

The adapted version of the Summary of Diabetes Self-Care Activity - SDSCA [11] consists of 15 items focusing on five main topics such as: diet; exercise; self-monitoring of blood glucose (SMBG); foot care; medication, and an additional item of smoking. There are also 6 supplementary questions which focus on participants' perceptions of the inclination of health care professionals to convey educational messages related to each item of self-care, except for the foot care item. In general, this tool is considered to have a good reliability with the Chronbach' alpha was 0.74 [29] and high inter-item correlation, with moderate testretest correlations [11].

\section{RESULTS AND ANALYSIS}

\subsection{Demographic}

Predominantly people attending the clinic that were recruited were aged over 40 years (97\%) with only $3 \%$ of the sample being aged between $18-39$ years. When compared to the target population, the total people attending the clinic aged between $15-44$ years was $12.31 \%$ compared with $7 \%$ of the recruited sample (aged 18-44 years), reflecting a low number of younger adults in both the target and study sample (Table 1). The majority of participants came from the regular income group (57), which comprised of private companies employees (17), pensioners (17), self-employed (12), government officers or civil servant (6), and professional (5). The remaining participants came from the non-regular income group (43) (Table 1).

This categorisation signifies which people had a stable and consistent source of income, as most Indonesian utilize a fee-for-service system of healthcare where people need to pay to receive a primary care services, except for those covered by the government, such as the poor, pensioner, and civil servants. Furthermore, amid the new development of health care service in Indonesia into a more insurance-based system, which required the people who are not eligible to be covered by the government to pay a monthly premium, has given the need to have a sufficient income in order to be able to have a sustainable health care service. Thus, the notion of having a regular and sufficient income is important particularly among people with a long term condition, such as diabetes, to establish sustainable healthcare delivery.

Levels of education were categorized into six items: no-formal, elementary (primary school), Junior high (secondary education), Senior high (College), Academy/University degree, and Master/PhD degree. Furthermore, the level of education was categorized into three levels of low (no-formal, elementary), medium (junior and senior high), and high (bachelor and Master and $\mathrm{PhD}$ ). The majority of participants came from a medium and high level of education with 38 participants from medium and 40 from high, whereas 22 participants came from lower level of education (Table 1).

\subsection{Levels of self-care}

The majority of the participants showed to have a moderate level of self-care (78) and the same number or participants were shared by the higher and lower level (11) (Table 2). This is in accordance to the study by Primanda (2011) that also found a moderate level of dietary behavior among the participants of her study in a hospital in Yogyakarta and other studies across Indonesian's setting [30]-[33]. In the whole sample there was more men (6) reported higher self-care than women (5) and more women (8) reported lower levels of self-care than men (3). The majority of both men and women, across all age groups reported moderate levels of self-care. People with a lower education level were more evident in the low self-care group and people with a higher education level in the high self-care group. Interestingly, more people with a regular income (9) reported a lower level of self-care than those with a non-regular income (2). A similar pattern of 
self-care activity to the whole sample was identified across the interview participants with moderate self-care activity being reported (Table 2).

Table 1. Demographic characteristics of questionnaire sample

\begin{tabular}{lcccc}
\hline \multirow{2}{*}{ Gender (n=number of people) } & \multicolumn{3}{c}{ Age - $\mathrm{n}=(\%)$} \\
\cline { 2 - 4 } & 43 & $18-39$ & $40-59$ & $\geq 60$ \\
\hline Male & 57 & $2(3.3)$ & $26(60.5)$ & $16(37.2)$ \\
Female & $\mathbf{1 0 0}$ & $\mathbf{3}$ & $29(50.90)$ & $26(45.6)$ \\
Total Number & & Education $(\mathrm{n}=)$ & $\mathbf{4 2}$ \\
\hline Occupation $(\mathrm{n}=)$ & 17 & No formal education & 5 \\
Private employee & 17 & Elementary (primary school) & 17 \\
Pensioner & 12 & Lower education level & $\mathbf{2 2}$ \\
Self-employed & 6 & Junior high (secondary) & 5 \\
Government officer & 5 & Senior high (College) & 33 \\
Professional & $\mathbf{5 7}$ & Medium education level & $\mathbf{3 8}$ \\
Regular income & 33 & Academy/University Degree & 36 \\
Housewife & 4 & Master/ PhD - higher degree & 4 \\
Labourer & 2 & Higher education level & $\mathbf{4 0}$ \\
Farmer & 2 &
\end{tabular}

Table 2. Levels of self-care

\begin{tabular}{|c|c|c|c|c|c|c|c|}
\hline \multirow{2}{*}{\multicolumn{2}{|c|}{ Overall level of self-care }} & \multicolumn{3}{|c|}{$\begin{array}{c}\text { Whole sample } \\
(n=100)\end{array}$} & \multicolumn{3}{|c|}{$\begin{array}{c}\text { Interview sample } \\
(n=24)\end{array}$} \\
\hline & & \multirow{2}{*}{$\begin{array}{c}\text { high } \\
11 \\
\end{array}$} & \multirow{2}{*}{$\frac{\text { moderate }}{\mathbf{7 8}}$} & \multirow{2}{*}{$\begin{array}{c}\text { low } \\
11 \\
\end{array}$} & \multirow{2}{*}{$\frac{\text { High }}{4}$} & \multirow{2}{*}{$\frac{\text { moderate }}{16}$} & \multirow{2}{*}{$\frac{\text { low }}{4}$} \\
\hline & & & & & & & \\
\hline \multirow{2}{*}{ Self-care/ gender } & Male & 6 & 33 & 3 & 2 & 7 & 1 \\
\hline & Female & 5 & 45 & 8 & 2 & 9 & 3 \\
\hline \multirow{3}{*}{ Self-care/ age } & $18-39$ & 0 & 2 & 1 & 0 & 1 & 1 \\
\hline & $40-59$ & 6 & 40 & 9 & 1 & 10 & 3 \\
\hline & $>60$ & 5 & 36 & 1 & 3 & 5 & 0 \\
\hline \multirow{3}{*}{ Self-care/ education } & Higher & 4 & 34 & 2 & 2 & 5 & 1 \\
\hline & Medium & 6 & 27 & 5 & 1 & 7 & 2 \\
\hline & Lower & 1 & 17 & 4 & 1 & 4 & 1 \\
\hline \multirow{2}{*}{ Self-care/ income } & Regular & 7 & 44 & 9 & 2 & 11 & 3 \\
\hline & Non-regular & 4 & 34 & 2 & 2 & 5 & 1 \\
\hline
\end{tabular}

Moreover, the current study has also found self-care is moderately practiced as separate notions instead of an integrated and comprehensive concept in diabetes management, in the lingering of the lack of adequate knowledge and the implementation of guideline, which represents the lack of structural support (Table 2). It is also in accordance to several studies across indonesian's setting which emphasize the unintegrated of diabetes management in practice [30]-[33].

From the questionnaire data participants reported that the most frequent self-care activities they were inclined to perform involved taking their medication $(\mathrm{M}=88 \%)$ and following a recommended diet $(\mathrm{D}=84 \%)$ to ensure their blood glucose remains stable (Figure 1).

Several participants emphasize the need to get medication and follow doctor's order as the first measure of treatment.

'The way is consulting to a doctor, got medications, and also from others information as well' (Mr Jawen)

'About the treatment (for diabetes), it varies, depend on the person. For me, I try to follow my doctor's advice to take the medicine. I take the medicine every morning,' (Mr Makmur)

Lack of information in regards of foot care was found from the majority of participants that explained behind the low score.

'No I haven't been told about foot care' (Mrs Suti)

'No, I haven't (known about foot care). Who will do the foot care treatment? Is it Dr Irfan? Would he do it? My feet are dirty' (Mrs Asti) 


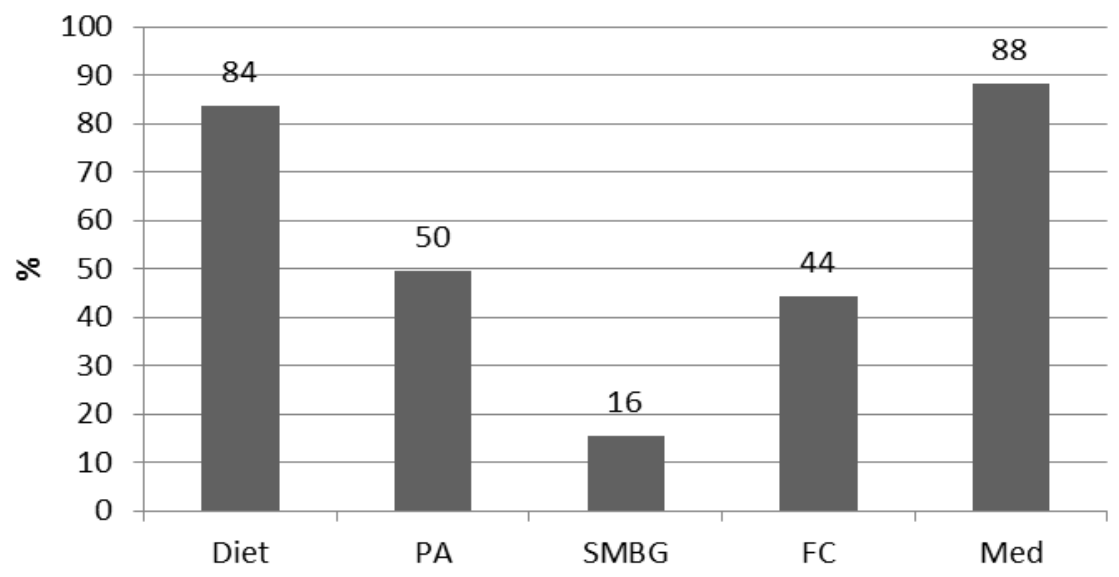

Figure 1. Perceived self-care activity (whole sample $n=100$ )

\subsection{Themes generation}

Further exploration found several themes that generated from the interviews, those are: education and knowledge, being in or out of control, Javanese way - sensitivity and surrender, peace of mind and role of Allah, poor access to health care.

\subsubsection{Education and knowledge}

One of the key findings of this study was the gaps in knowledge of effective diabetes management and the concept of self-care, despite the majority of participants demonstrating moderate self-care activity. Furthermore, the majority of interview participants were unaware of any structured educational program in place and many, when describing their activity, highlighted a complete lack of understanding for any particular self-care activity.

'No, there is no (any educational session)' (Mrs Siti)

'I have no idea (about any educational programs)' (Mrs Asti)

Participants regarded the doctor or dietician as the two key sources of information from the health care professionals. Furthermore, in regards of how to gain knowledge, Persadia has been promoted by participants as an organisation where they can access valuable knowledge on how to manage their condition. Indeed, this is particularly evident for those people with limited funds; Persadia was the main source of diabetes management and education.

'Especially before Ramadan...We were told that during Ramadan we didn't stop exercising, by ripping newspapers with our feet. It was counted as an exercise as well... That's it. So, since I have joined (the aerobic) at the PKU...my knowledge has getting better especially about diabetes' (Mr Ripan)

'Well, yesterday at the (aerobic session)... the dietician has told us... Use this and that. If you want to eat egg, eat this much, using dummies. There were various toys there, egg, cake, bread all from plastic, you see. They were belongs to the medical school' (Mr Adil)

'Blood check was done every week at weekly exercise in hospital after the exercise. Before that we will get a blood pressure check. After the exercise, one will get a blood sugar check for 8,000 rupiah. You would have to pay for a 13,000 in the lab. There, you would only have to pay only 8,000.' (Mrs Ismi).

\subsubsection{Being in or out of control}

The perceptions of who is taking the responsibility for the outcome of someone else's effort might influence the adherence to self-care activity. Furthermore, the main self-agency factor behind this lack of practices is the attitude of putting something or someone else over themselves in taking responsibility in managing themselves, which resemblances the notion of external health locus of control [21],[34]. Several participants have relied on husband, wife or other important person in taking care of themselves, or even to rely on their doctors without even considered to ask what has happened to their own body. 
'I walk when instructed by my children, usually on early morning, but I also take concern on my children's family, especially the grandchildren, getting up in time, preparing breakfast for them, most of the time' (Mrs Tata)

'I can't resist not drinking something like... the like of sweet ice tea, coffee...sometimes, when I visit my friend, they serve me with that kind of drink which I couldn't resist... But, for me, it's not a big deal (forgetting the medication). I don't hesitate to eat the meal...sometimes I take more (food) or less than it, it depends to my mood' (Mr Makmur)

'No, I haven't (asked anything). Dr L had never given me any recommendations. It's just “what do you feel, mam?"' (Mrs Siti)

Although, there are several others who relied on their own effort to look after their condition, even to adjust the dosage of medication.

'Well, that (the ability to control myself and the blood sugar control) comes from my own abilities. If I follow the doctor, I have to eat three times a day, and the vitamins, there are a lot of them. But for me, it is my own (ability)' (Mr Fajar)

'Well, (if I were invited for a meal) I got medication from the doctor, so I raised the dose a little bit... Usually, one extra tablet. If usually I took two tablets, then I took three. There is a Glimepirid, which usually 4 tablets a day. I had one in the morning along with 2 tablets of Metformin. If I had to go to an occasion, I'd take three' (Mr Jawen)

\subsubsection{Javanese way - sensitivity and surrender}

A notion of Javenese culture of tepo seliro or being sensitive to others' interest was influential in how people behaved towards their diabetes management, whether it was not pushing to access free services, not wanting to bother anyone else, not taking too long with a doctor so other people would be seen quicker.

'Being sensitive...It actually tepo seliro (being sensitive to other's situation). Tepo seliro is we respect others. Tepo Seliro...Yes I know (my rights to have a free service), since I had public health insurance. But to the Javanese, let say, being sensitive. We would feel uncomfortable, because it is free, why bother to ask for things...then again, no one said that the service was paid by the government, but my heart wouldn't just do it' (Mr Jawen)

'The time with the doctor was so tight...I mean...I could not have a long consultation time... I was concern of the other patients which was a lot of them waiting... in case I was disturbing them' (Mrs Ismi) things slow.

Being a Javanese means having to look for others' sake in managing social relationship, taking

'Basically, according to Javanese way, everything we do we should do it slowly... don't bother to think anything, if you get tired, so be it... after you got better then you can start to work again' (Mrs Suti)

'So, there will come a time, the Javanese would say, 'urip itu kan kayak muter', life is like a circle, sometimes we were up, and at that time, I was at the bottom. Eventually, it would go... there's no way that we always kept at the bottom' (Mr Arif)

\subsubsection{Peace of mind and role of Allah or God}

Several participants mentioned the importance of keeping the peace of mind to manage their wellbeing, which to some extent is believed to help them in maintaining their blood sugar level. This notion emerged among participants from the intertwined influence of Javanese culture and Islamic values. Indeed, this finding emphasized the notion of the limitation of the questionnaire to capture what lies beyond the social aspects of human being.

'Peace of mind is number one to support us in curing the illness. The more we believe (in Allah), the more we will be in a calmness' (Mr Makmur).

for me, peace of mind plays big part. If we are happy, no thoughts burden, it will keep the diseases away.' (Mr Jawen) 
God served as an important external factor that was responsible in influencing their effort to selfcare for their diabetes.

'Although, I don't work, but the one that gives life is God. So, one who grows a plant, must also waters it, so one way or another, we must be fulfilled by God' (Mr Jawen)

\subsubsection{Poor access to health care}

The introduction of the Jamkesmas card for the poor has certainly began to increase access to diabetes education and regular blood sugar monitoring, weekly for those members of Persadia, for people who used to excluded from accessing health care due to their economic status.

'Before that pak Dukuh (the head of the village) had given me some.. well.. I am poor so pak Dukuh is giving his attention to me (by giving the Jamkesmas card). For instance, if I go to the hospital and need something to reduce the burden. All my three children have it. My husband has it. I do too' (Mrs Suti)

'I didn't pay in hospital. I used Jamkesmas. I just came to puskemas asking for a referral, came to $P K U$, free. All was free, free consultation, free lab check...Otherwise, I would have pay a lot, at least 200 thousands rupiah for every check.' (Mrs Siti)

The government provides the basic healthcare service with the provision of Jamkesmas card or Jaminan Kesehatan Masyarakat (Community Health Insurance) for the poor, and Askes or Asuransi Kesehatan (Health Insurance) for the civil servant. In order to get the benefit of the service, it has a particular health service system, including the referral system that must be followed. The general practitioner is served as the first line of treatment and the gate keeper for referring to the specialist.

'It is free (to go to the county hospital), but had to go there every three days, go to communal clinic again, find hospital reference, too much to do, as if we don't have anything else to do. Other than doing my own business, going about to the hospital every three days makes me tired' (Mr Jawen). 'I should go to the puskesmas, then Sarjito hospital. At that time... I had to wake up at 4 and went to Sarjito to take the number... even when I went after dawn, I was in queue in the position number 100. So, I should do the whole proces for the whole day. Let say...the laboratorium...it opens at 8, if I got number 80, I got my blood drawn at 10. Then, I should eat and after two hours, I should go back. So, it would be finished at least at 2. The next day, I should come back again to take the result and see the internist for a consultation. After that, the internist would give a reference to the cardiologist for the next two days' (Mr Sadi)

\section{CONCLUSION}

The majority of people sampled highlighted a moderate level of self-care predominantly taking responsibility for the managing their medication, diet and occasional exercise. There was no evidence of any structured education programmes within the health care sector to educate people on diabetes management; education took more the format of providing ad hoc information during a consultation.

Persadia offered health seminars, an excellent source of information and support, and the people accessing these demonstrated more in depth and accurate diabetes education and knowledge. Furthermore, this can be served as an evidence of how social support can play an important role in managing individuals' condition.

This study also revealed the role of religion and Javanese culture in influencing people in managing their daily self-care. Being a Javanese has played a role in maintaining daily management of the illness; either, as a hindrance or opportunity to self-care. While, healthcare services, social support and also religious beliefs, the belief of the main role of Allah, have played as structures that influencing individuals in managing their daily live in diabetes management. These tenets have emerged and embeded within the notion of self-agency, such as locus of control and self-efficacy that have played as important determinant factors in maintaining their daily activity.

\section{REFERENCES}

[1] International Diabetes Federation, "IDF Diabetes Atlas, 6th edn. (Sixth ed.)", Brussels, Belgium, International Diabetes Foundation, 2013.

[2] International Diabetes Federation, "IDF Diabetes Atlas-2007 (3rd edition)", 2007. 
[3] World Bank, "The World Bank", World Population, 2010. Retrieved 11 February 2012, 2012, from http://search.worldbank.org/all?qterm=world\%20population.

[4] Shaw, JE., Sicree, RA., Zimmet, PZ., "Global estimates of the prevalence of diabetes for 2010 and 2030", Diabetes Research and Clinical Practice, vol. 87, pp. 4-14, 2010.

[5] International Diabetes Federation, "IDF-Guideline-for-Type-2-Diabetes”, Belgium, IDF, 2012.

[6] World Health Organization, "Diabetes", Media Centre, 2012. Retrieved 6 March 2013, 2013, from www.who.int/mediacentre/factsheets/fs312/en/index.html

[7] Commision on Health Development and Research, "Riset Kesehatan Dasar, RISKESDAS 2010", Riset Kesehatan Dasar, 2010.

[8] World Health Organization, "Indonesia. Country Health Profiles", WHO, 2006. http://www.searo.who.int/LinkFiles/Indonesia_CHP-Indonesia.pdf.

[9] Department of Health UK, "Supporting people with long term conditions to self-care. A guide to developing local strategies and good practice", Leeds, Department of Health, 2006.

[10] World Health Organization, "Self-care in the context of Primary Health Care Report of the Regional Consultation", New Delhi, World Health Organization, Regional Office for South East Asia, 2009.

[11] Toobert, DJ., Hampson, SE., Glasgow, RE., "The summary of diabetes self-care activities measure: results from 7 studies and a revised scale", Diabetes Care, vol/issue: 23(7), pp. 943-950, 2000. doi: 10.2337/diacare.23.7.943.

[12] Toljamo, M., Hentinen, M., "Adherence to self-care and glycaemic control among people with insulin-dependent diabetes mellitus", Journal of Advanced Nursing, vol/issue: 34(6), pp. 780-786, 2001. doi: 10.1046/j.13652648.2001.01808.x.

[13] Perkeni, "Konsensus Pengelolaan dan Pencegahan Diabetes Melitus tipe 2 di Indonesia 2011 (the 2011 Indonesian Concensus of Prevention and Management of type 2 Diabetes Mellitus), 2011.

[14] Sinorita, H., Saadah, Jazakillah, S., "Effects of dietary pattern and education on glycemic control in patients with t2d in sardjito", Acta Medica Indonesia, 2004.

[15] Soewondo, P., Soegondo, S., Suastika, K., Pranoto, A., Soeatmadji, DW., Tjokroprawiro, A., "The DiabCare 2008 study-Outcomes on control and complications of type 2 diabetic patients in Indonesia", Medical Journal Indonesia, vol/issue: 19(4), 2010.

[16] Soewondo, P., "Current practice in management of t2d in Indoneisa: Results from the International Diabetes Management Practices Study”, Journal Indonesian Medical Association, vol/issue: 61(12), pp. 8, 2011.

[17] World Health Organization European Regional Office, "Young people's health in context. Health Behavior in School-aged Children (HSBC) study: international report from the 2001/2002 survey", In C. Currie, C. Roberts, A. Morgan, R. Smith, W. Settertobulte, O. Samdal, VB. Rasmussen (Eds.), "Health Policy for Children and Adolescents No 4, World Health Organization, 2001.

[18] Cockerham, WC., "The Sociology of Health Behavior and Health Lifestyles", In C. E. Bird, P. Conrad, AM. Fremont (Eds.), "Handbook of Medical Sociology (Fifth Edition ed.)", New Jersey, Prentice Hall, 2000.

[19] Emirbayer, M., Mische, A., "What is Agency?", The American Journal of Sociology, vol/issue: 103(4), pp. 63, 1998.

[20] Heisler, M., Smith, DM., Hayward, RA., Krein, SL., Kerr, EA., "How Well Do Patients' Assessments of Their Diabetes Self-Management Correlate With Actual Glycemic Control and Receipt of Recommended Diabetes Services?", Diabetes Care, vol/issue: 26(3), pp. 738-743, 2003. doi: 10.2337/diacare.26.3.738.

[21] Andrews, L., Stefurak, J., Mehta, S., "Between a rock and a hard place? Locus of control, religious problem solving and psychological help-seeking", Mental Health, Religion \& Culture, vol/issue: 14(9), pp. 855-876, 2011.

[22] Grace, C., Begum, R., Subhani, S., Kopelman, P., Greenhalgh, T., "Prevention of type 2 diabetes in British Bangladeshis: qualitative study of community, religious, and professional perspectives", BMJ, vol. 337, 2008. doi: 10.1136/bmj.a1931.

[23] Sowattanangoon, N., Kotchabhakdi, N., Petrie, KJ., "The influence of Thai culture on diabetes perceptions and management", Diabetes research and clinical practice, vol/issue: 84(3), pp. 245-251, 2009. doi: 10.1016/j.diabres.2009.02.011.

[24] Lim, JW., Baik, OM., Ashing-Giwa, KT., "Cultural Health Beliefs and Health Behaviors in Asian American Breast Cancer Survivors: A Mixed-Methods Approach”, Oncology Nursing Forum, vol/issue: 39(4), pp. 388-397, 2012.

[25] Harandy, TF., Ghofranipour, F., Montazeri, A., Anoosheh, M., Bazargan, M., Mohammadi, E., . . . Niknami, S., "Muslim breast cancer survivor spirituality: coping strategy or health seeking behavior hindrance?", Health Care Women Int, vol/issue: 31(1), pp. 88-98, 2010. doi: 10.1080/07399330903104516.

[26] Carbone, ET., Rosal, MC., Torres, MI., Goins, KV., Bermudez, OI., "Diabetes self-management: perspectives of Latino patients and their health care providers", Patient Educ Couns, vol/issue: 66(2), pp. 202-210, 2007. doi: 10.1016/j.pec.2006.12.003.

[27] Samuel-Hodge, CD., Headen, SW., Skelly, AH., Ingram, AF., Keyserling, TC., Jackson, EJ., . . . Elasy, TA., "Influences on day-to-day self-management of type 2 diabetes among African-American women: spirituality, the multi-caregiver role, and other social context factors", Diabetes Care, vol/issue: 23(7), pp. 928-933, 2000.

[28] Lager, JM., "Relationship among Religious Coping, Psychosocial Factors, and Quality of Life in Individuals with Type 2 Diabetes, (PhD), Texas A\&M University, 2006.

[29] Creswell, JW., "Research design. Qualitative, Quantitative, and Mixed Methods Approaches", (Fourth ed.). London, Sage, 2014.

[30] Primanda, Y., Kritpracha, C., Thaniwattananon, P., "Dietary behaviors among patients with t2d in Jogjakarta", Nurse Media Journal of Nursing, vol/issue: 1(2), pp. 13, 2011 
[31] Flora, R. Hikayat, Purwanto, S., "Pelatihan senam kaki pada penderita diabetes mellitus dalam upaya pencegahan komplikasi diabetes pada kaki (diabetes foot) [Training on feet exercise among diabetic patient in preventing diabetic foot complication]", Jurnal Pengabdian Sriwijaya, 2013.

[32] Sari, CWM., "Pengaruh program edukasi perawatan kaki berbasis keluarga terhadap perilaku perawatan kaki pada pasien diabetes mellitus tipe 2 di wilayah kerja Puskesmas Pasirkaliki Kota Bandung", Pustaka Ilmiah Universitas Padjadjaran, 2013.

[33] Sutiawati, M., Jafar, N., Yustini, "The influence of nutrition education towards, the increase of knowledge, dietary and blood sugar levels among type 2 diabetes mellitus outpatient in Lanto'dg Pasewang public hospital Jeneponto", Universitas Hasanudin, Makassar, 2013.

[34] Wallston, KA., "Multidimensional Health Locus of Control (MHLC) Scale", 2007. Retrieved from http://www.nursing.vanderbilt.edu/faculty/kwallston/mhlcscales.htm. 